\title{
Results of surgery for epiretinal membranes and their recurrences
}

\author{
Ralf Grewing, Ulrich Mester
}

\begin{abstract}
Aims/Background-This study was performed to identify factors predictive for recurrence of idiopathic and secondary epiretinal membranes after vitrectomy. Long term visual outcome was determined and compared with eyes without recurrence of epiretinal tissue.

Methods-Out of 350 consecutive cases vitrectomised for removal of epiretinal macular membranes, 42 patients (42 eyes) with recurrence of epiretinal membranes were re-examined and their records reviewed. Recurrence of epiretinal membranes was determined by new appearance of epiretinal tissue or abnormal sheen of the central retina. The preoperative findings, best postoperative and final visual acuity of these patients were compared with a comparable cohort of eyes without recurrence after removal of macular pucker (131 eyes). The eligibility criterion was a follow up of at least 6 months.
\end{abstract}

Results-The best postoperative (0.46 (SD $0.24)$ ) and the final visual acuity (0.39 $(0.26))$ of eyes with recurrent membranes (42 eyes) was statistically better than preoperative vision $(0.27(0.22)) \quad(p=0.0003$ and $0 \cdot 0089)$. Because of reduced or distorted vision eight of the 42 eyes underwent a revitrectomy during the follow up (mean 23 months). Best postoperative visual acuity $(0 \cdot 50(0 \cdot 21))$ and final visual acuity $(0.47(0.25))$ of eyes which received a second vitrectomy $(n=8)$ were not statistically different from the 32 eyes with recurrence of epiretinal tissue but without revitrectomy $(p=0.253$ and 0.343$)$. In addition, eyes with recurrence showed no different visual outcome compared with eyes without recurrence of epiretinal membranes after vitrectomy $(p=0.84)$. Recurrence of epiretinal membranes was correlated with neither the type of membrane (thick or thin) nor incomplete membrane removal during pars plana vitrectomy.

Conclusion-This study demonstrates the overall favourable visual prognosis of patients with vitrectomy for macular pucker, even with recurrence of the premacular membrane.

(Br F Ophthalmol 1996; 80: 323-326)

Pars plana vitrectomy for removal of epiretinal membranes is a well established surgical procedure with favourable results. One reason for renewed occurrence of reduced or distorted vision is the recurrence of the macular pucker. Because regrowth of epiretinal tissue after vitrectomy is a rare event, ${ }^{1}$ prognostic data or risk factors for recurrence of epiretinal membranes are still speculative. Therefore, we performed this study to evaluate the functional outcome of eyes with recurrent epiretinal membranes to identify possible risk factors.

\section{Patients and methods}

Out of 350 consecutive cases that had been vitrectomised for removal of epiretinal membranes, 42 eyes $(12 \%)$ with regrowth of epiretinal tissue after vitrectomy could be identified. Recurrence of epiretinal membrane was determined by new appearance of epiretinal tissue or abnormal sheen of the central retina during the follow up, suggesting that additional epiretinal tissue was present again. The differentiation between a pathological reflex of the macular region and a remarkable amount of epiretinal tissue is difficult and may be subject to individual assessment.

Important for the definition of regrowth was the new appearance of epiretinal changes during the follow up. The distortion of retinal vasculature including the foveal region and straightening of longitudinal vessels were not necessary for the definition of recurrent epiretinal membrane. Only eight of the 42 patients $(19 \%)$ complained of renewed occurrence of reduced vision or metamorphopsia making revitrectomy necessary. The 42 eyes with recurrence of macular pucker were compared with 131 eyes vitrectomised for macular pucker without recurrence of epiretinal tissue.

All eyes included in this study had a follow up of more than 6 months, and before pars plana vitrectomy no further macular pathology was present - for example, impending or full thickness holes, macular oedema, or age related maculopathy. Because of these eligibility criteria 177 cases were unavailable for statistical analysis.

Preoperative findings (preoperative visual acuity, lens status, idiopathic or secondary development of the epiretinal membranes, presence of systemic diseases), intraoperative findings (incomplete removal of the epiretinal membrane, thickness, and adherence of the membrane) and postoperative findings (best postoperative and final visual acuity, retinal detachment, and cataract development of eyes with regrowth of epiretinal membranes) (42 eyes) were compared with eyes without recurrence after removal of macular pucker (131 eyes). The type of membrane (thick or thin) was determined by the surgeon. All membranes classified as thin were translucent. 
Often the only ophthalmoscopic clue to their presence was a 'Cellophane' light reflex from the inner retinal surface and/or fine irregular crinkles on the retinal surface. Membranes classified as thick were opaque in most cases. Only five translucent membranes were classified as thick by the surgeon because the epiretinal membranes consisted of a thickness normally found only in opaque membranes. Except for these five cases (3\%) the classification used is in accordance with the often used classification of translucent and opaque membranes which can be made by biomicroscopy preoperatively. ${ }^{1}$ At each visit the macula was examined by biomicroscopy. The analysed intraoperative findings were commented on in all operative reports.

The mean follow up after vitrectomy was 23 (range 6-53) months with no statistical difference in mean follow up between eyes with and without regrowth of epimacular tissue.

Statistical analyses were performed by comparison of two paired samples based on ranks, comparison of two independent samples based on pairs (Mann-Whitney), and contingency tables using the STATGRAPHICS software package (Statistical Graphics Co).

\section{Results}

This series included 73 male (42\%) and 100 female $(58 \%)$ patients, ranging in age from 27 to 87 (median 68) years. Recurrence of epiretinal membranes was not correlated with the patients' age $(p=0.99) ; 85$ were right eyes and 88 were left eyes. Thirty one patients also had preretinal macular fibrosis in the fellow eye. The most frequent complaints were blurred, reduced, and/or distorted vision. Preoperative fluorescein angiography was not routinely performed, although it was performed before and after vitrectomy in selected cases. Twenty patients $(12 \%)$ had a history of diabetes mellitus, but no diabetic retinopathy proved by fluorescein angiography. Sixty four patients (37\%) had systemic hypertension, but systemic hypertension was no risk factor for recurrence of epiretinal membranes after vitrectomy $(p=0 \cdot 657)$.

\section{ANATOMICAL AND FUNCTIONAL RESULTS}

The statistical analysis of best postoperative and final visual acuity showed a significant improvement for the vitrectomised eyes even if recurrence of epiretinal tissue occurred. For the 131 vitrectomised eyes without recurrence of epiretinal tissue the best postoperative mean visual acuity of $0.46(\mathrm{SD} 0.25)(\mathrm{p}=2.92 \mathrm{E}-$ 13) and the final mean visual acuity 0.38 $(0 \cdot 25)(p=6 \cdot 39 E-5)$ was significantly better than the preoperative mean visual acuity of $0 \cdot 29(0 \cdot 19)$. Also, the 42 eyes with recurrence of epiretinal membranes showed a significantly improved best postoperative mean visual acuity of $0.46(0.24)(\mathrm{p}=3.24 \mathrm{E}-4)$ and final mean visual acuity of $0.39(0.26)(\mathrm{p}=8.9 \mathrm{E}-$ 3 ) compared with the preoperative mean visual acuity of $0 \cdot 27(0 \cdot 22)$.

No statistically significant difference of the best $(p=0.84)$ as well as final $(p=0 \cdot 89)$ visual acuity between eyes with recurrence $(n=42)$ and without recurrence $(n=131)$ of epiretinal tissue exists. Only in eight cases did a revitrectomy become necessary because of new appearance of reduced visual acuity and/or metamorphopsia. During revitrectomy the epimacular membrane could be removed from the fovea in all cases, but in three eyes minor remnants were left at the posterior pole. In these eyes with incomplete tissue removal the membranes had only a little structural strength, were friable, and tended to shred. In all eight eyes the final visual acuity after revitrectomy was better than before the first vitrectomy (Table 1). The mean interval between vitrectomy and revitrectomy for recurrent macular pucker was $13.4(\mathrm{SD} 7 \cdot 7)$ months.

Best $(0.50(0.21))$ and final visual acuity $(0.47(0.25))$ of the eight eyes which received a second vitrectomy for removal of a recurrent membrane were not statistically different from the 34 eyes with recurrence of epiretinal tissue but without revitrectomy (best visual acuity: $0.45(0.25)$, final visual acuity $0.37(0.26))$ $(\mathrm{p}=0.253$ and 0.343$)$.

\section{POSTOPERATIVE COMPLICATIONS}

The main complication after vitrectomy was the development or progression of lens opacities. Cataract was the reason for the slight visual impairment during the follow up, shown as the mean difference between best and last visual acuity. In the total group (173 eyes), 103 of the 143 phakic eyes $(72 \%)$ had the preoperative appearance of cataract formation. The severity of lens opacities was graded as: mild (64 eyes), moderate (36), severe (four). The location was not specified. Twenty six eyes $(15 \%)$ were pseudophakic and four eyes were aphakic before pars plana vitrectomy. Capsulotomy had been performed in five of the 26 pseudophakic eyes.

In the total group of 173 investigated eyes, 76 of 143 preoperatively phakic eyes $(53 \%)$ developed cataract; $38(50 \%)$ of them received phacoemulsification and posterior chamber lens (PCL) implantation into the capsular bag during the follow up. The average time between vitrectomy and cataract surgery was $16 \cdot 8$ (SD 9.7) months.

The incidence of retinal detachment after vitrectomy was $4 \%$ ( $7 / 173$ eyes) in the total group. Only one of these seven eyes had been operated on because of macular pucker following retinal detachment surgery. The six

Table 1 Visual acuity (VA) after vitrectomy (vit) and revitrectomy (revit) for recurrent epimacular membranes

\begin{tabular}{|c|c|c|c|c|c|c|c|}
\hline & $\begin{array}{l}V A \\
\text { before } \\
\text { vit }\end{array}$ & & $\begin{array}{l}\text { Best VA } \\
\text { after } \\
\text { vit }\end{array}$ & $\begin{array}{l}V A \\
\text { before } \\
\text { revit }\end{array}$ & & $\begin{array}{l}\text { Best } V A \\
\text { after } \\
\text { revit }\end{array}$ & $\begin{array}{l}\text { Last } V A \\
\text { after } \\
\text { revit }\end{array}$ \\
\hline Patient 1 & 0.05 & & 0.63 & 0.25 & $\mathbf{R}$ & 0.8 & 0.8 \\
\hline Patient 2 & 0.05 & I & $0 \cdot 2$ & 0.2 & $\mathrm{E}$ & $0 \cdot 2$ & $0 \cdot 1$ \\
\hline Patient 3 & $0 \cdot 16$ & ${ }_{T}^{1}$ & 0.5 & $0 \cdot 4$ & I & $0 \cdot 4$ & $0 \cdot 25$ \\
\hline Patient 4 & $0 \cdot 16$ & $\mathrm{R}$ & 0.5 & 0.4 & ${ }_{T}^{1}$ & 0.5 & 0.5 \\
\hline Patient 5 & $0 \cdot 2$ & E & $0 \cdot 2$ & 0.2 & $\mathrm{R}$ & $0 \cdot 32$ & $0 \cdot 32$ \\
\hline Patient 6 & $0 \cdot \overline{4}$ & $\mathrm{C}$ & $0 . \overline{8}$ & 0.32 & $\mathrm{E}$ & 0.5 & 0.5 \\
\hline Patient 7 & 0.4 & $\begin{array}{l}1 \\
0\end{array}$ & 0.63 & 0.63 & $\mathrm{~T}$ & $0 \cdot 8$ & $0 \cdot 8$ \\
\hline Pati & 0.5 & $M$ & 0.63 & 0.4 & & 0.5 & 0.5 \\
\hline Mean & 0.24 & & 0.51 & 0.35 & $\stackrel{M}{\mathbf{Y}}$ & 0.5 & 0.47 \\
\hline
\end{tabular}


other eyes had idiopathic epiretinal membranes. In all eyes the retina was reattached with scleral buckling techniques or sulphur hexafluoride gas tamponade. The average time between pars plana vitrectomy and retinal detachment was 3.75 months.

POSSIBLE RISK FACTORS FOR RECURRENCE To identify possible risk factors predictive for the recurrence of epiretinal membranes after vitrectomy we analysed the influence of several preoperative and intraoperative findings.

\section{(1) Thickness of the epiretinal membrane}

One hundred and seven eyes of the total group $(62 \%)$ had a thin epiretinal membrane. Preoperatively, most of these eyes showed only an abnormal sheen of the macula. The nature of the preretinal membrane was not a prognostic factor for regrowth $(p=0 \cdot 849)$.

\section{(2) Adherence of the epiretinal membrane}

The epiretinal tissue proved to be firmly adherent to the underlying retina in $\mathbf{4 5}$ of all eyes $(26 \%)$. Again, this factor was not correlated with recurrence $(p=0 \cdot 828)$.

\section{(3) Complete/incomplete removal of the epiretinal membrane}

In all vitrectomised eyes the membrane could be removed completely from the fovea, but in 25 eyes $(14 \%)$ remnants were left at the posterior pole. Our data showed no significant correlation between incomplete membrane removal and recurrence $(p=0 \cdot 828)$.

\section{(4) Idiopathic/secondary epiretinal membranes} One hundred and seventeen eyes $(68 \%)$ of the total group had no associated ocular disorder or previous ocular surgery. In these cases the epiretinal membrane was classified as idiopathic regardless of the presence of systemic diseases for example, hypertension. In 56 cases (32\%) the condition occurred after several ocular diseases and surgical procedures including cataract removal (30 eyes), retinal reattachment surgery (12 eyes), laser photocoagulation/cryo (10 eyes), trauma (one eye), ocular inflammation (one eye), and retinal vascular abnormalities (two eyes). The cause of epiretinal membrane formation had no statistically significant influence on the recurrence of preretinal tissue $(p=0.971)$. Separate statistical analysis was performed for cases with idiopathic as well as secondary epiretinal membranes. But the evaluation of these subgroups also showed no statistically significant risk factors for regrowth of epiretinal membranes after vitrectomy. Also, no significance could be calculated if eyes with epiretinal tissue following cataract surgery were not classified as secondary membranes.

\section{Discussion}

Out of 350 consecutive cases vitrectomised for macular pucker 42 eyes with recurrence of epiretinal tissue could be evaluated. They were compared with a cohort of 131 eyes without recurrence of epiretinal tissue. In some reports the recurrence rate of macular pucker is calculated on the basis of the reappearance of sizeable amounts of epiretinal tissue. Eyes which showed an increased sheen of the internal limiting membrane, suggesting presence of a thin epiretinal membrane, were not considered. ${ }^{2}$ This may contribute to the fact that regrowth after removal of epiretinal membranes is reported as a rare postoperative event. ${ }^{134}$ In our study eyes with increased sheen during follow up were also included in the group with recurrence of epiretinal tissue. Because of this morphological definition it is not surprising that only eight of the 42 patients with recurrent epiretinal membranes complained of newly reduced or distorted vision making revitrectomy necessary. Five of the eight eyes had idiopathic epiretinal membranes. Recurrence of removed idiopathic membranes is a rare event ${ }^{5}$ and revitrectomy for recurrent idiopathic membranes is reported only in single cases. ${ }^{167}$ In our patients no significant correlation between recurrence of epiretinal membranes and final visual acuity could be proved. All revitrectomised eyes retained a long term visual acuity better than before the first vitrectomy.

The association between vitrectomy and later cataract development or progression is well known. ${ }^{89}$ In our study 76 of 143 phakic eyes $(53 \%)$ developed lens opacities during the follow up of nearly 2 years. In 38 eyes ( $50 \%$ ) uneventful phacoemulsification and PCL implantation into the capsular bag was performed during follow up.

Trese et al ${ }^{10}$ and Mester ${ }^{11}$ have suggested that translucent epiretinal membranes carry a better prognosis than opaque membranes. Eyes with Cellophane-like epiretinal membranes in the series of Rice and associates ${ }^{12}$ did less well than eyes with thicker epiretinal membranes. Other authors ${ }^{13}$ were not able to evaluate a statistical significance in postoperative visual acuity between eyes with thin or thick membranes or opaque or translucent membranes. The recurrence rate in our series was not influenced by the nature or the adherence of the epiretinal membranes.

It was speculated that incomplete removal of membranes may account for regrowth in some cases. ${ }^{14-16}$ Rice et al reported incomplete membrane removal in $6 \%$ and late recurrence of epiretinal membranes in $4 \% .{ }^{12}$ But no correlation between these facts had been analysed by the authors. In 25 (14\%) of our vitrectomised eyes remnants of epiretinal tissue were left at the posterior pole. In eyes with incomplete tissue removal the membranes had limited structural strength, were friable, and tended to shred. Often these membranes were firmly adherent to the retina throughout the zone of contact. But incomplete removal of the epiretinal membranes was no risk factor for regrowth.

The incidence of recurrence of epiretinal membranes is low and is reported to be up to $6 \%$ in idiopathic cases. ${ }^{214} 1718$ The incidence 
of secondary membrane regrowth is up to $33 \% .{ }^{17}$ In our study no correlation between primary or secondary epiretinal membrane and the rate of regrowth could be detected. This result was also obtained if the 30 eyes with earlier cataract procedures were classified as idiopathic epiretinal membranes.

Preretinal macular fibrosis has been reported not only in association with ocular diseases, but also with several systemic disorders. These include arteriosclerosis, diabetes mellitus, and hypertension. ${ }^{1920}$ In our series, 64 of 173 investigated eyes $(37 \%)$ were from patients who had hypertension. This is comparable with the study of Appiah et $a^{21}$ in which the proportion of patients with vascular hypertension was $36.4 \%$. In our study, associated systemic disorders such as diabetes mellitus without diabetic retinopathy and hypertension did not influence the recurrence rate. Our study was not prospective and the calculation of the recurrence rate may be biased by the fact that not all 350 consecutive eyes which were operated on for macular pucker could be observed over a minimal follow up period of 6 months. In conclusion, we were unable to prove any statistically significant risk factor for the regrowth of macular pucker after vitrectomy.

Presented in part at the XIXth meeting of the Club Jules Gonin, 9-13 September 1994, Versailles, France.

1 Pesin SR, Olk RS. Incidence and management of complications associated with pars plana vitrectomy for premacular
fibroplasia. In: Olk RS, ed. New approaches to vitreoretinal fibroplasia. In: Olk RS, ed. New approaches to vitreoretinal
surgery. International Ophthalmology Clinics. Vol 32, surgery. International Ophthalmology Clinics. Vol
Number 2. Boston: Little, Brown, 1992: 95-104.

2 Michels RG. Vitrectomy for macular pucker. Ophthalmology 1984; 91: 1384-8.
3 Pepsin SR, Olk RJ, Grand MG, Boniuk I, Arribas NP, Thomas MA. Vitrectomy for premacular fibroplasia. Ophthalmology 1991; 98: 1109-14.

4 Pilkerton AR, Gilbert WS, Perraut Sr LE, Perraut Jr LE Garfinkel RA. Idiopathic preretinal fibrosis: a review of 237 cases. Ophthalmic Surg 1992; 23: 113-5.

5 Piguet B, Gonvers $M$. Traitment chirurgical de la fibrose maculaire epiretinienne: experience lausanoise. Klin Monatsbl Augenheilkd 1990; 196: 357-9.

6 De Juan Jr E, Lambert HM, Machemer R. Recurrent proliferations in macular pucker, diabetic retinopathy, and retrolental fibroplasialike disease after vitrectomy. Graefes Arch Clin Exp Ophthalmol 1985; 223: 174-83.

7 Maguire AM, Smiddy WE, Nanda SK, Michels RG, de la Cruz Z, Green WR. Clinicopathologic correlation of recurrent epiretinal membranes after previous surgical recurrent epiretinal membranes

8 De Bustros S, Thompson JT, Michels RG, Enger C, Rice TA, Glaser BM. Nuclear sclerosis after vitrectomy for idiopathic epiretinal membranes. Am $\mathcal{F}$ Ophthalmol 1988; 105: $160-4$.

9 Grewing R, Mester U. Linsentrübungen anch Pars-planaVitrektomie bei diabetischer Vitreoretinopathie und Mrur pucker Fortschr Ophthalmol 1990; 87: 440-2.

10 Trese MT, Chandler DB, Machemer R. Macular pucker. I. Prognostic criteria. Graefes Arch Clin Exp Ophthalmol Progessic criteria

11 Mester U. Vitrektomie bei epiretinaler Gliose. Fortschr Ophthalmol 1988; 85: 267-9.

12 Rice TA, de Bustros S, Michels RG, Thompson JT, Debanne SM, Rowland DY. Prognostic factors in vitrectomy for epiretinal membranes of the macula. Ophthalmology 1986; 93: 602-10.

13 McDonald HR, Verre WP, Aaberg TM. Surgical management of idiopathic epiretinal membranes. Ophthalmology 1986; 93: 978-83.

14 Margherio RR, Cox Jr MS, Trese MT, Murphy PL, Johnson J, Minor LA. Removal of epiretinal membranes. Johnson J, Minor LA. Removal of
Ophthalmology 1985; 92: 1075-83.

15 Wilkinson CP. Recurrent macular pucker. Am f Ophthalmol 1979; 88: 1029-31.

16 Zarbin MA, Michels RG, Green WR. Epiretinal membrane contracture associated with macular prolapse. $A m \mathcal{F}$ Ophthalmol 1990; 110: 610-8.

17 Margherio RR. [Discussion of Michels RG.] Vitrectomy for macular pucker. Ophthalmology 1984; 91: 1387-8.

18 Michels RG. Vitreous surgery for macular pucker. $A m \mathcal{J}$ Ophthalmol 1981; 92: 628-39.

19 Wise GN. Clinical feature of idiopathic preretinal macular fibrosis. Am ₹ Ophthalmol 1975; 79: 349-57.

20 Wiznia RA. Natural history of idiopathic preretinal macular fibrosis. Ann Ophthalmol 1982; 14: 876-8.

21 Appiah AP, Hirose T, Kado M. A review of 324 cases of idiopathic premacular gliosis. Am $\mathcal{F}$ Ophthalmol 1988; 106: 533-5. 